\title{
The Effect of Carbamazepine Against Glutamate-induced Cytotoxicity in the C6 Cell Line
}

\author{
Ahmet Kemal Filiz \\ Departments of Physiology, Sivas Cumhuriyet University, School of Medicine, Sivas, Turkey \\ Aysegul Ozturk (Corresponding author) \\ Departments of Physiology, Sivas Cumhuriyet University, School of Medicine, Sivas, Turkey \\ E-mail: fztaysegul@yahoo.com
}

\begin{abstract}
Purpose: Recent studies have shown that carbamazepine has positive effects on nervous system. However, its effect on glutamate-induced cytotoxicity in glial cells is still unclear. Our study was designed to investigate the effect of carbamazepine against glutamate-induced cytotoxicity in C6 glial cells and involved mechanisms.
\end{abstract}

Material and Methods: In this study, the C6 glioma cell line was used. Four cell groups were prepared to evaluate the effect of carbamazepine on glial cell death after glutamate-induced cytotoxicity. The control group was without any treatment. Cells in the glutamate group were treated with $10 \mathrm{mM}$ glutamate for 24 hours. Cells in the carbamazepine group were treated with various concentrations $(3.75,7.5,15$, and $30 \mu \mathrm{M})$ of carbamazepine for 24 hours. Cells in the carbamazepine + glutamate group were pre-treated with various concentrations $(3.75,7.5,15$, and $30 \mu \mathrm{M})$ of carbamazepine for 1 hour and then exposed to $10 \mathrm{mM}$ glutamte for 24 hours. The cell viability was evaluated by XTT assay. Total antioxidant status (TAS), total oxidant status (TOS), tumor necrosis factor alpha (TNF- $\alpha$ ), and malondialdehyde (MDA) levels in the cells were measured by commercial kits.

Results: Carbamazepine at the concentration of $30 \mu \mathrm{M}$ significantly increased the cell viability in C6 cells after glutamate-induce cytotoxicity $(\mathrm{p}<0.05)$. CBZ $(30 \mu \mathrm{M})+$ glutamate significantly increased TOS levels in C6 cells compared to control untreated control cells $(\mathrm{p}<0.05)$, while it did not change TAS level ( $p>0.05)$. Moreover, carbamazepine did not change TNF- $\alpha$ level $(p>0.05)$ and increased MDA $(\mathrm{p}<0.05)$ level in C6 cells after glutamate-induced cytotoxicity.

Conclusion: Carbamazepine decreases glial cell death after glutamate-induced cytotoxicity in C6 cells. While carbamazepine produced protective effective in the acute process, long-term usage may increase oxidative damage and cause cell death.

\section{Special Issue of Health Sciences}

DOI: $10.7176 /$ JSTR/7-08-09

\section{Introduction}

Neurodegenerative diseases are examples of neurological disorders that affect people all over the world (Chin \& Vora, 2014). The primary characteristics of these disorders are neuronal damage and loss, and the processes involved include inflammation, oxidative stress, misfolded protein accumulation, excitotoxicity, and others (Tovar-y-Romo et al., 2009).

Excitotoxicity is a specific type glutamate-mediated neurotoxicity (TW et al., 2014). Glutamate is an excitatory neurotransmitter that plays a critical effect in the central nervous system's (CNS) plasticity $(\mathrm{H}$ et al., 1997; Nampoothiri et al., 2014). Glutamate is necessary for axon guidance and neuronal growth, brain development and maturation, and synaptic plasticity in health and disease, additionally being required for rapid synaptic transmission that is essential for neuron-to-neuron communication (TW et 
al., 2014). Glutamate performs its effects with its own receptors. There are two types of receptors in this system: ionotropic and metabotropic. The ionotropic receptor family is divided into three categories: Alpha amino-3-hydroxy-5-methyl-4 isoxazolepropionic acid (AMPA) receptors, N-methylD-aspartate (NMDA) receptors, and kainate receptors (ML, 2005). Glutamate acts as a neurotoxic when its concentration is too high, causing cell death (Ç. S et al., 2019). Excess glutamate damages cellular components, including mitochondria, as well as promotes the production of reactive oxygen species (ROS) and cell death (A et al., 2001).

Excitotoxicity, which is induced by excessive glutamate activation and results in excessive calcium ion inux into the cell, is the main mechanism in the development of various disorders ( $\mathrm{C}$ et al., 2006). Calcium influx into the cell causes mitochondrial disorder, which causes the cell to go into apoptosis process (A. M \& M, 2003).

Glial cells are non-neuronal cells that play a vital role in the CNS, such as maintaining homeostasis, supporting and safeguarding neurons (KR, 2004). Therefore, reducing oxidative stress in glial cells is crucial for the treatment of neurodegenerative (T \& M, 2021).

Carbamazepine (CBZ) is an antiepileptic drug (AED) with a carboxamide derivative that is used to treat partial-onset seizures (Livingston et al., 1967) as well as various neurological and psychiatric diseases (RM \& S, 2004). It is considered to modulate the uptake, release, and receptor binding of neurotransmitters in dopaminergic, glutamatergic, and serotonergic systems by blocking or enhancing voltage-gated $\mathrm{Na}^{+}, \mathrm{K}^{+}$, and $\mathrm{Ca}^{2+}$ channels (AF et al., 2002). Several pharmacodynamic researches, on the other hand, reveal that the mechanisms of clinical effect of CBZ are more complex, involving the calcium-induced calcium-releasing system (Y. S et al., 2007), voltage-sensitive calcium channel regulation (T. S et al., 2012; Y. S et al., 2007; Yamamura et al., 2009), and glutamate release (Yamamura et al., 2009). CBZ has also been investigated in vivo and in vitro as a neuroprotective drug (JC, 2003; Woronowicz et al., 2013).

Nevertheless, its effect on glutamate-induced cytotoxicity in C6 glial cells and the mechanisms that underlie it are yet unknown. The effect of CBZ against glutamate-induced cytotoxicity in C6 glial cells involved in oxidative stress pathways was investigated in this research.

\section{Materials And Methods}

\subsection{Cell Culture}

Because of its glutamate-induced cytotoxicity, the C6 Glioma (CRL107) cell line was selected in this investigation (Kritis et al., 2015). The American Type Culture Collection provided C6 Glioma cell lines. The American Type Culture Collection (ATCC) provided C6 Glioma cell lines. The cells were cultured in DMEM (Thermo Fisher Scientific, Altrincham, UK) containing 10\% Fetal Bovine Serum (FBS) (Sigma-Aldrich Co., St Louis, MO, USA), and 1\% L-glutamine (Sigma-Aldrich Co., St Louis, MO, USA) and $1 \%$ penicillin/streptomycin (Sigma-Aldrich Co., St Louis, MO, USA). The cells were incubated at $37^{\circ} \mathrm{C}$ in a humidified environment containing $5 \% \mathrm{CO} 2$.

\subsection{Drug Administration}

CBZ (Sigma-Aldrich Co., St Louis, MO, USA) and glutamate (Sigma-Aldrich Co., St Louis, MO, USA) were dissolved in DMEM, and stock solutions were prepared before treatment.

\subsection{Glutamate-Induced Cytotoxicity}

To examine the effect of CBZ on glutamate-induced cytotoxicity, four cell groups were formed. There was no treatments for the control group. The glutamate-induced group's cells were given $10 \mathrm{mM}$ glutamate for 24 hours. CBZ was given to cells in the CBZ group at varied concentrations $(3.75,7.5$, 15 , and $30 \mathrm{M}$ ) for 24 hours. Cells in the CBZ+glutamate group were pre-treated with different concentrations $(3.75,7.5,15$, and $30 \mu \mathrm{M})$ of $\mathrm{CBZ}$ for 1 hour and then administered to $10 \mathrm{mM}$ glutamate for 24 hours.

\subsection{Cell Viability Assay}

The XTT test was used to determine cell viability (Roche Diagnostic, MA, USA). C6 Glioma cells were seeded at a density of $1 \times 104$ cells per well in $100-\mu \mathrm{L}$ DMEM and cultured overnight before being treated with CBZ. The glutamate-induced cytotoxicity method was carried out as described previously. The medium was withdrawn the next day after 24 hours of incubation, and the wells were cleaned twice with phosphate-buffered saline (PBS). In the last stage, $100 \mu \mathrm{L}$ of DMEM without phenol red and

68 | P a g e

www.iiste.org 
$50 \mu \mathrm{L}$ of XTT labeling solution were added to each well, and the plates were kept at 37 degrees Celsius for 4 hours. After shaking the plates, the absorbance was measured at $450 \mathrm{~nm}$ using an ELISA microplate reader (Thermo Fisher Scientific, Altrincham, UK). All of the tests were repeated three times, and cell viability was calculated as a percentage of viable cells relative to the control, which were untreated cells (Figure 1).

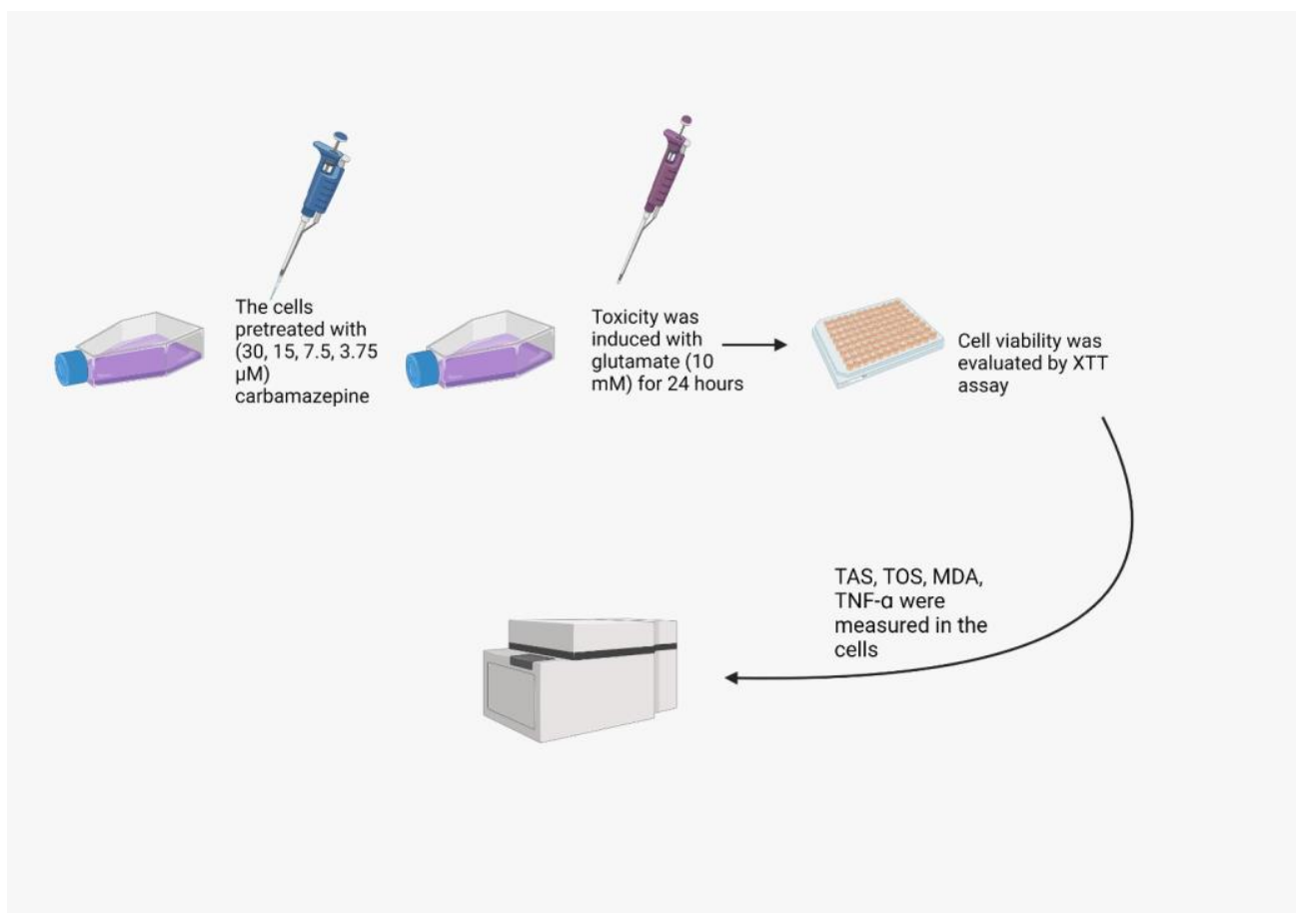

Figure1. Experimental design of study (created by BioRender).

\subsection{Preparation of Cell Homogenates}

Each group's cells were collected in sterile tubes. The supernatant was removed after centrifugation at $2000 \mathrm{rpm}$ for about 10 minutes. The cells in the tubes were suspended by diluting the cell suspension with PBS (pH: 7.4) to a cell concentration of approximately 1 million $/ \mathrm{ml}$. The cells were damaged by repeated freeze-thaw cycles, which allowed the interior components to let out. At a temperature of $4^{\circ} \mathrm{C}$, cells were centrifuged for 10 minutes at $4000 \mathrm{rpm}$. The supernatants were then collected and subjected to biochemical analysis. Total protein levels in the samples were determined using the Bradford protein assay kit (Merck Millipore, Darmstadt, Germany).

\subsection{Measurement of TAS and TOS}

TAS concentrations in cell supernatants we The method is based on detecting the absorbance of colored dianisidyl radicals during free radical reactions, commencing with the formation of hydroxyl radicals in the Fenton reaction, to monitor the rate of the reaction of free radicals.re measured using an automated assay method developed by Erel before $(\mathrm{O}, 2004)$. Antioxidants in tissue samples should inhibit coloration in proportion to their amounts $(\mathrm{O}, 2004)$. Micromolar Trolox equivalents per milligram tissue protein were used to get the results ( $\mu$ mol Trolox Eq/mg protein). The amounts of tissue TOS in cell supernatants were measured using Erel's automated assay technique $(\mathrm{O}, 2005)$. The approach enables for estimating TOS levels by measuring tissue levels of ferric ions with the use of xylenol orange because ferrous ion is oxidized to ferric ion when appropriate quantities of oxidants are available in the medium. The calibration of the test was done with hydrogen peroxide $(O, 2005)$. The assay's results were given in micromolar hydrogen peroxide equivalents per milligram tissue protein ( $\mu \mathrm{mol} \mathrm{H} \mathrm{O}_{2} \mathrm{O} \mathrm{Eq} / \mathrm{mg}$ protein).

\subsection{Statistical Analysis}

The data were analyzed as a mean with a standard error of the mean (SEM). SPSS Version 23.0 for Windows was used to analyze the data. A one-way analysis of variance (ANOVA) was used to analyze 
the data, and the posthoc Tukey test was used to determine the differences between the experimental groups. A statistically significant result of $\mathrm{p}<0.05$ was accepted.

\subsection{RESULTS}

\subsection{Carbamazepine's effect on cell viability after glutamate-induced oxidative damage}

Using a XTT cell proliferation test, the protective effects of CBZ against glutamate-induced cytotoxicity in C6 cells were assessed. The effects of increasing CBZ concentrations $(3.75-30 \mu \mathrm{M})$ on cell viability in both control and glutamate-induced C6 cells were investigated in this study. The cells were initially treated with increasing concentrations $(3.75,7.5,15$, and $30 \mu \mathrm{M})$ of CBZ for 1 hour and then incubated with or without $10 \mathrm{mM}$ glutamate-induced for the next 24 hours. Figure 2 shows that preincubating C6 cells with glutamate for 24 hours dramatically decreased cell survival when compared to control untreated cells ( $\mathrm{p}<0.05$; Figure 2). Furthermore, as compared to glutamateinduced C6 cells, the tested doses of 30 M CBZ increased cell survival.

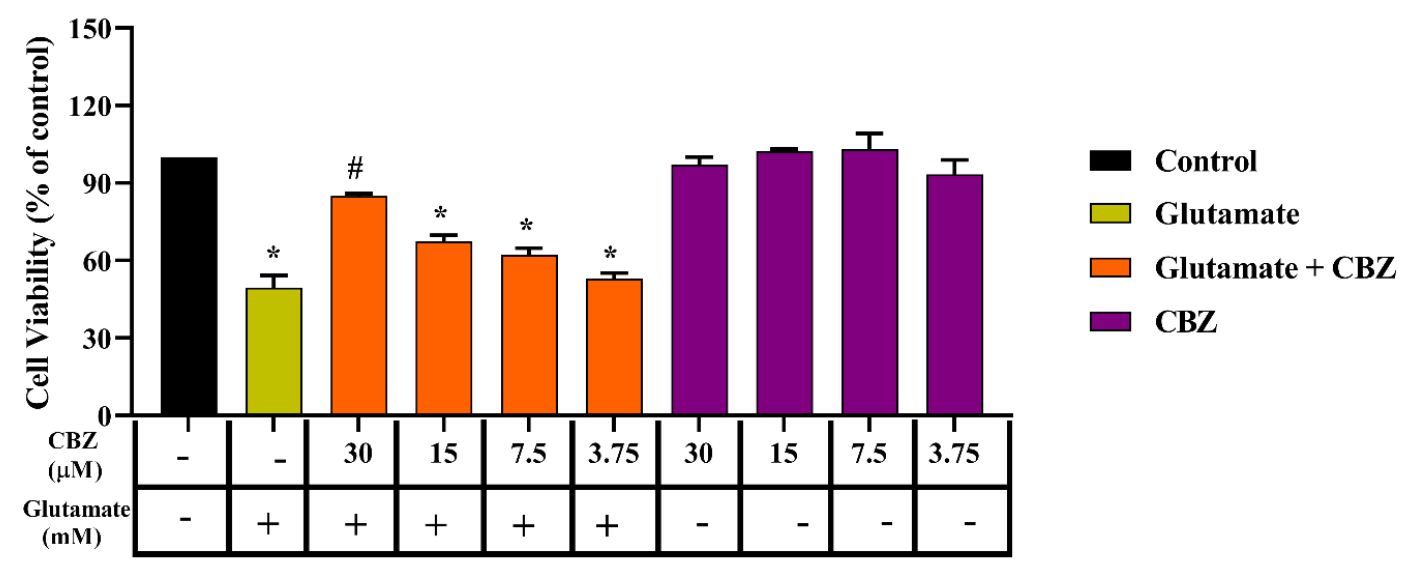

Figure 2. Effect of carbamazepine on cell survival in C6 cells after glutamate-induced cytotoxicity. The data are expressed as mean \pm standard error mean. *p $<0.05$ as compared with control-untreated group; \# $\mathrm{p}<0.05$ compared with glutamate-treated.

\subsection{Carbamazepine's effect on TAS and TOS levels after glutamate-induced cytotoxicity in C6 cells}

The cells were treated with the single doses $(30 \mu \mathrm{M})$ of glutamate for 1 hour and then incubated or not incubated with $10 \mathrm{mM}$ glutamate for the next 24 hours. As shown in Figure 3, glutamate treatment had no effect on the TAS level of C6 cells when compared to untreated control cells ( $p>0.05$; Figure 3A). Furthermore, when CBZ was compared to an untreated control, the levels of TAS in C6 cells was unchanged. Furthermore, when CBZ was compared to untreated control ( $p>0.05$; Figure 3A) and glutamate-treated C6 cells ( $p>0.05$; Figure 3A), the level of TAS in C6 cells was unchanged. Furthermore, preincubating C6 cells with glutamate for 24 hours increased TOS levels significantly as compared to control-untreated cells ( $<<0.05$; Figure $3 \mathrm{~B})$. On the other hand, the CBZ $(30 \mu \mathrm{M})+$ glutamate significantly increased TOS levels in C6 cells compared with control untreated cells ( $\mathrm{p}<0$. 05; Figure 3B).

\subsection{Carbamazepine's effect on TNF- $\alpha$ after glutamate-induced cytotoxicity in C6 cells}

The ELISA tests were carried out to determine the effects of CBZ on TNF- following glutamateinduced cytotoxicity in C6 cells. The cells were treated with the single dose $(30 \mu \mathrm{M})$ of CBZ. The cells were treated a single dose $(30 \mathrm{M})$ of CBZ for 1 hour before being cultured or not with $10 \mathrm{mM}$ glutamate for the next 24 hours. When C6 cells were pre-incubated with glutamate for 24 hours, the level of TNF- did not affect when compared to control untreated cells ( $p>0.05$; Figure 4$)$. 

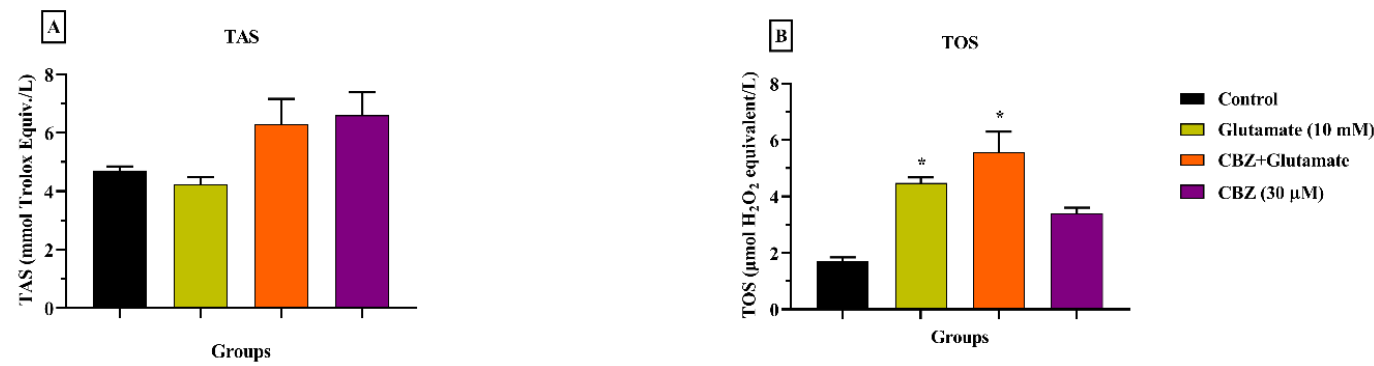

Figure 3. Effect of carbamazepine on TAS and TOS levels in C6 cells after glutamate-induced cytotoxicity. The data are expressed as mean \pm standard error mean. $* p<0.05$ and as compared with control-untreated group.

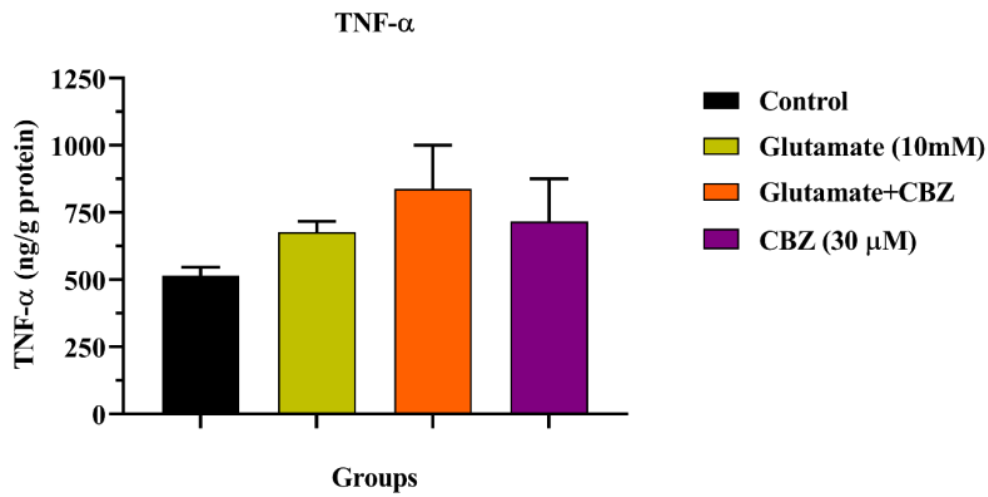

Figure 4. Effect of carbamazepine on Tnf- $\alpha$ levels in C6 cells after glutamate-induced cytotoxicity.

The data are expressed as mean \pm standard error mean. ${ }^{*} p<0.05$ and as compared with controluntreated group.

\subsection{Carbamazepine's on MDA after glutamate-induced cytotoxicity in C6 cells}

After glutamate-induced cytotoxicity in C6 cells, the effects of CBZ on MDA were assessed using ELISA kits. Cells were pretreated with a single dose of CBZ $(30 \mu \mathrm{M})$ for 1 hour then incubated with 10 $\mathrm{mM}$ glutamate or not. Cells were incubated for 24 hours after treatment. When C6 cells were preincubated with glutamate for 24 hours, the MDA level did not alter when compared to untreated control cells ( $>$ > 0.05; Figure 5). CBZ (30 M) + glutamate, on the other hand, significantly increased MDA levels in C6 cells when compared to control untreated cells (p 0. 05; Fig. 5).

MDA

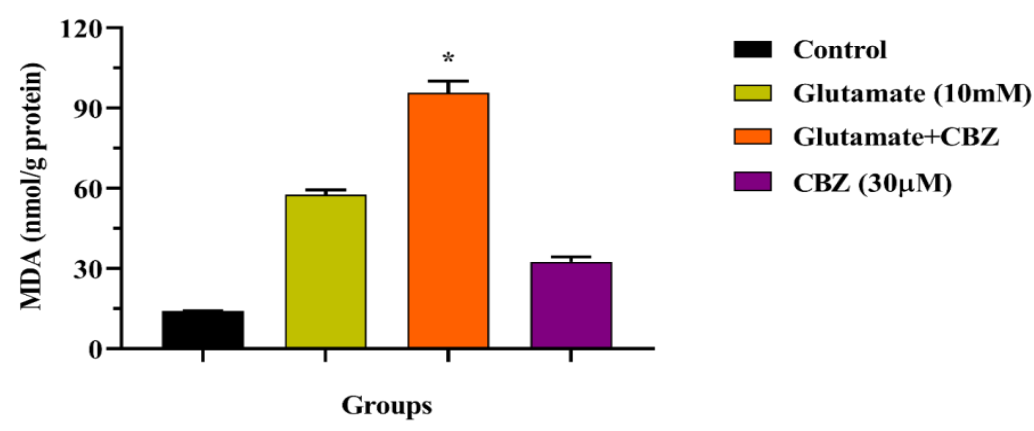

Figure 5. Effect of carbamazepine on MDA levels in C6 cells after glutamate-induced cytotoxicity. The data are expressed as mean \pm standard error mean. $* p<0.05$ and as compared with controluntreated group. 


\section{Discussion}

In this study is the first to investigate at the effect of Carbamazepine on glutamate-induced cytotoxicity in C6 cells. CBZ pretreatment enhanced C6 cell survival and decreased cell death after glutamateinduced cytotoxicity. CBZ pretreatment increased TOS levels in C6 cells but had no effect on TOS levels after glutamate-induced cytotoxicity. Furthermore, CBZ increased MDA levels in C6 cells while having no effect on TNF-a levels after glutamate-induced cytotoxicity in C6 cells.

Recent studies have focused on voltage-gated sodium channel (VGSC-) inhibitors, which may be able to defend the existing neurons from further damage. Sun et al. reported that fenamates (mefenamic acid and flufenamic acid), voltage-gated sodium channel inhibitors, protect against glutamate-induced damage in SH SY5Y cells (Sun et al., 2020).

The main mechanism of CBZ is thought to be the blockage of voltage-gated sodium channels (RL, 2002). However pharmacodynamic studies report the mechanisms of clinical action of CBZ are more complicated with calcium-induced calcium-releasing system (Y. S et al., 2007), glutamate release (O. M et al., 1998; Yamamura et al., 2009), and modulation of voltage-sensitive calcium channels (Y. S et al., 2007; Zhu et al., 2002).

Okada et al., investigated the effects of acute and chronic administration of CBZ on astroglial Lglutamate release using primary cultured astrocytes. Their research demonstrated this that both acute and chronic treatment of CBZ reduced excitatory astroglial glutamatergic transmission related with IP3-R and AMPA-R (O. M et al., 2019).

Oxidative stress is the reaction in which there is an imbalance between the production and elimination of ROS and reactive nitrogen species, which creates the possibility of organic damage. It is suggested that oxidative stress plays an active role in the development of neurodegenerative diseases (SJ \& BC, 2010). Several researches on genetic studies and animal models have shown an enhance both in mitochondrial oxidative stress and consequent cell damage after recurrent seizures (AJ \& M, 1995; LP \& M, 2006; MR et al., 2000). Oxidative stress can be induced by a variety of diseases or by being exposed to specific substances. It has been suggested that an increase in the amount of active oxygen metabolites or a decrease in the activity of antioxidative defense systems may lead to an increase in seizure frequency (JA \& JS, 1991; LJ \& JJ, 1981). This oxidative stress is controlled by antioxidant mechanisms (JM, 2000). The organism is protected by this system against the damaging effects of substances (Tutanc et al., 2015). Antioxidant action's function in the treatment of AEDs is controversial. The relationship between membrane lipid peroxidation, neuronal excitotoxicity, antioxidants, and AEDs was reviewed by Hamed and Abdellah (SA \& MM, 2004). Ekici et al., in their experimental study, showed that valproic acid pretreatment, which is an AED before epileptic seizures, has a DNA damage-increasing effect (EKİCI \& TAŞKIRAN, 2020).

Oxidative damage induced by CBZ was demostrated by some previously conducted researches (C. M et al., 2000; G. M et al., 2004). Decreased TAS and increased levels were also showed by some in vitro researches (ZH, P, et al., 2010; ZH, V, et al., 2010). Similarly, our results showed that CBZ pretreatment increased TOS and MDA levels in glutamate-induced cells.

$\mathrm{TNF} \alpha$ - is a cytokine that is produced by immune cells and is a proinflammatory cytokine. It has been suggested that TNF- $\alpha$ causes CNS disorders by increasing neuroinflammation in the brain (DiSabato et al., 2016)(Ransohoff, 2016). Ichiyama et al. found that CBZ had no effect on TNF- $\alpha$ in LPS-induced THP-1 cells ( $\mathrm{T}$ et al., 2000). . In addition, Okada et al reported that acute administration of CBZ did not alter Tnf- $\alpha$ levels, whereas chronic administration did not inhibit Tnf-a (O. M et al., 2019).

Carbamazepine found to have a significant role in glial cell survival, according to our results. Because glial cells are important in neurodegenerative disorders, carbamazepine might be used as a complementary therapy for the treatment neurodegenerative diseases. While carbamazepine produced protective effective in the acute process, long-term usage may increase oxidative damage and cause cell death. Therefore, it must be supported by more research.

There are some potential limitations in the research. This investigation was used in C6 rat glioma cells instead of than primer glial cells. Our method is not sufficient to explain all processes causing carbamazepine's effects on C6 glial cells. More research is needed to understand the effects of carbamazepine on glial cells.

\section{Conclusion}

The results of this study demostrated that carbamazepine reduced cell death against glutamate-induced in C6 glial cells. However, the protective effect of CBZ has been demonstrated with acute 
administration. At the same time, carbamazepine increased oxidative damage in this process. This effect could possibly occur through MDA. However, further study is required to answer the questions about the possible mechanisms involved.

\section{Acknowledgment}

The authors would like to thank the Sivas Cumhuriyet University, School of Medicine, CUTFAM Research Center, Sivas, Turkey, for providing the necessary facilities to conduct this study. We would like to thank Ziad Joha for helpful critique and Assistant Professor Ahmet Sevki Taskiran for his critical suggestion and article editing.

\section{Authors' Contributions}

Ahmet Kemal Filiz: concept/design, drafting of manuscript, data analysis; statistical analysis, drafting of manuscript; Ayşegül Öztürk: concept/design, critical revision of the manuscript, data analysis. All authors read and approved the final manuscript.

\section{Conflict of Interest}

The authors declare that they have no conflict of interest

\section{References}

A, A., P, C., A, B., S, G., E, M., \& S, P. (2001). Glutamate neurotoxicity, oxidative stress and mitochondria. FEBS Letters, 497(1), 1-5. https://doi.org/10.1016/S0014-5793(01)02437-1

AF, A., P, S.-D.-S., CM, C., \& AP, C. (2002). Mechanisms of action of carbamazepine and its derivatives, oxcarbazepine, BIA 2-093, and BIA 2-024. Neurochemical Research, 27(1-2), $121-$ 130. https://doi.org/10.1023/A:1014814924965

AJ, B., \& M, B. (1995). Oxygen free radicals in rat limbic structures after kainate-induced seizures. Free Radical Biology \& Medicine, 18(6), 993-1002. https://doi.org/10.1016/08915849(94)00218-9

C, M., M, D., \& MV, S.-G. (2006). Glutamate-mediated glial injury: mechanisms and clinical importance. Glia, 53(2), 212-224. https://doi.org/10.1002/GLIA.20275

Chin, J. H., \& Vora, N. (2014). The global burden of neurologic diseases. Neurology, 83(4), 349. https://doi.org/10.1212/WNL.0000000000000610

DiSabato, D. J., Quan, N., \& Godbout, J. P. (2016). Neuroinflammation: the devil is in the details. Journal of Neurochemistry, 139, 136-153. https://doi.org/10.1111/JNC.13607

EKİĊ, M., \& TAŞKIRAN, A. Ş. (2020). The Effect of Valproic Acid on DNA Damage and Apoptosis After Pentylenetetrazole-induced Epileptic Seizure Generated in the Hippocampus and Cortex in Rats. I $\breve{g} d ı r$ Üniversitesi Fen Bilimleri Enstitüsü Dergisi, 10(4), 2924-2931. https://doi.org/10.21597/JIST.730381

H, K., T, M., S, S., J, K., T, H., Y, G., \& E, N. (1997). Activation and involvement of p38 mitogenactivated protein kinase in glutamate-induced apoptosis in rat cerebellar granule cells. The Journal of Biological Chemistry, 272(30), 18518-18521. https://doi.org/10.1074/JBC.272.30.18518

JA, J., \& JS, R. (1991). Oxygen free radicals and brain dysfunction. The International Journal of Neuroscience, 57(1-2), 1-17. https://doi.org/10.3109/00207459109150342

JC, R. (2003). Neuroprotective effects of anticonvulsants in rat hippocampal slice cultures exposed to oxygen/glucose deprivation. Neuroscience Letters, 335(3), 167-170. https://doi.org/10.1016/S0304-3940(02)01193-X 
JM, M. (2000). The evolution of free radicals and oxidative stress. The American Journal of Medicine, 108(8), 652-659. https://doi.org/10.1016/S0002-9343(00)00412-5

KR, J. (2004). Glial cells. The International Journal of Biochemistry \& Cell Biology, 36(10), 18611867. https://doi.org/10.1016/J.BIOCEL.2004.02.023

Kritis, A. A., Stamoula, E. G., Paniskaki, K. A., \& Vavilis, T. D. (2015). Researching glutamate induced cytotoxicity in different cell lines: a comparative/collective analysis/study. Frontiers in Cellular Neuroscience, 0, 91. https://doi.org/10.3389/FNCEL.2015.00091

Livingston, S., Villamater, C., Sakata, Y., \& Pauli, L. L. (1967). Use of Carbamazepine in Epilepsy: Results in 87 Patients. JAMA, 200(3), 204-208. https://doi.org/10.1001/JAMA.1967.03120160070009

LJ, W., \& JJ, R. (1981). Antiperoxidant pretreatment and iron-induced epileptiform discharges in the rat: EEG and histopathologic studies. Neurology, 31(1), 63-69. https://doi.org/10.1212/WNL.31.1.63

LP, L., \& M, P. (2006). Seizure-induced changes in mitochondrial redox status. Free Radical $\begin{array}{llll}\text { Biology } \quad \text { Medicine, } & \text { 40(2), }\end{array}$ https://doi.org/10.1016/J.FREERADBIOMED.2005.08.026

M, A., \& M, T. (2003). Molecular mechanisms of calcium-dependent neurodegeneration in excitotoxicity. Cell Calcium, 34(4-5), 325-337. https://doi.org/10.1016/S0143-4160(03)001416

M, C., A, Y., \& M, S. (2000). The effects of carbamazepine and valproic acid on the erythrocyte glutathione, glutathione peroxidase, superoxide dismutase and serum lipid peroxidation in epileptic children. Pharmacological Research, 41(4), 423-425. https://doi.org/10.1006/PHRS.1999.0603

M, G., YK, G., S, A., S, A., M, K., \& K, K. (2004). Effects of add-on melatonin administration on antioxidant enzymes in children with epilepsy taking carbamazepine monotherapy: a randomized, double-blind, placebo-controlled trial. Epilepsia, 45(12), 1636-1639. https://doi.org/10.1111/J.0013-9580.2004.17604.X

M, O., K, F., T, S., \& Y, U. (2019). Carbamazepine Attenuates Astroglial L-Glutamate Release Induced by Pro-Inflammatory Cytokines via Chronically Activation of Adenosine A 2A Receptor. International Journal of Molecular Sciences, 20(15). https://doi.org/10.3390/IJMS20153727

M, O., Y, K., K, M., K, W., T, K., \& S, K. (1998). Interaction between Ca2+, K+, carbamazepine and zonisamide on hippocampal extracellular glutamate monitored with a microdialysis electrode. British Journal of Pharmacology, 124(6), 1277-1285. https://doi.org/10.1038/SJ.BJP.0701941

ML, M. (2005). Glutamate receptor ion channels. Current Opinion in Neurobiology, 15(3), 282 288. https://doi.org/10.1016/J.CONB.2005.05.004

MR, G., E, J., S, S., AJ, R., \& V, H. (2000). CNS oxidative stress associated with the kainic acid rodent model of experimental epilepsy. Epilepsy Research, 39(1), 63-71. https://doi.org/10.1016/S0920-1211(99)00111-4

Nampoothiri, M., Reddy, N. D., John, J., Kumar, N., Kutty Nampurath, G., \& Rao Chamallamudi, M. (2014). Insulin blocks glutamate-induced neurotoxicity in differentiated SH-SY5Y neuronal cells. Behavioural Neurology, 2014. https://doi.org/10.1155/2014/674164 
O, E. (2004). A novel automated method to measure total antioxidant response against potent free $\begin{array}{llll}\text { radical } & \text { reactions. } & \text { Clinical } & \text { Biochemistry, }\end{array}$ https://doi.org/10.1016/J.CLINBIOCHEM.2003.10.014

O, E. (2005). A new automated colorimetric method for measuring total oxidant status. Clinical Biochemistry, 38(12), 1103-1111. https://doi.org/10.1016/J.CLINBIOCHEM.2005.08.008

Ransohoff, R. M. (2016). How neuroinflammation contributes to neurodegeneration. Science, 353(6301), 777-783. https://doi.org/10.1126/SCIENCE.AAG2590

RL, M. (2002). In Antiepileptic Drugs. In R. . M. B. . P. E. Mattson (Ed.), Epilepsia: Vol. 36 Suppl 2 (5th ed.). https://doi.org/10.1111/J.1528-1157.1995.TB05996.X

RM, H., \& S, K. (2004). A review of the evidence for carbamazepine and oxcarbazepine in the treatment of bipolar disorder. The International Journal of Neuropsychopharmacology, 7(4), 507-522. https://doi.org/10.1017/S1461145704004651

S, Ç., Ç, S., G, K., E, D., A, T., M, Ö., M, A., TK, N., \& A, T. (2019). Acute glufosinate-based herbicide treatment in rats leads to increased ocular interleukin-1 $\beta$ and c-Fos protein levels, as well as intraocular pressure. Toxicology Reports, 6, 155-160. https://doi.org/10.1016/J.TOXREP.2019.01.004

S, T., S, Y., M, N., E, M., \& M, O. (2012). Effect of lamotrigine and carbamazepine on corticotropin-releasing factor-associated serotonergic transmission in rat dorsal raphe nucleus. Psychopharmacology, 220(3), 599-610. https://doi.org/10.1007/S00213-011-2506-Y

S, Y., M, O., G, Z., \& S, K. (2007). Carbamazepine prevents breakdown of neurotransmitter release induced by hyperactivation of ryanodine receptor. Neuropharmacology, 52(7), 1538-1546. https://doi.org/10.1016/J.NEUROPHARM.2007.02.009

SA, H., \& MM, A. (2004). Trace elements and electrolytes homeostasis and their relation to antioxidant enzyme activity in brain hyperexcitability of epileptic patients. Journal of Pharmacological Sciences, 96(4), 349-359. https://doi.org/10.1254/JPHS.CRJ04004X

SJ, C., \& BC, Y. (2010). Mitochondrial matters of the brain: mitochondrial dysfunction and oxidative status in epilepsy. Journal of Bioenergetics and Biomembranes, 42(6), 457-459. https://doi.org/10.1007/S10863-010-9317-4

Sun, J. F., Zhao, M. Y., Xu, Y. J., Su, Y., Kong, X. H., \& Wang, Z. Y. (2020). Fenamates Inhibit Human Sodium Channel Nav1.2 and Protect Glutamate-Induced Injury in SH-SY5Y Cells. Cellular and Molecular Neurobiology, 40(8), 1405-1416. https://doi.org/10.1007/S10571-02000826-1

T, I., K, O., JM, L., T, M., T, H., \& S, F. (2000). Sodium valproate inhibits production of TNFalpha and IL-6 and activation of NF-kappaB. Brain Research, 857(1-2), 246-251. https://doi.org/10.1016/S0006-8993(99)02439-7

Taskiran Ahmet Sevki, E. M. (2021). The Protective Effect of Hydralazine against Hydrogen Peroxide (H2O2)-Induced Oxidative Damage in C6 Glial Cell Line. Türk ve Fen Sağlık Dergisi, $2,8-15$.

Tovar-y-Romo, L. B., Santa-Cruz, L. D., \& Tapia, R. (2009). Experimental models for the study of neurodegeneration in amyotrophic lateral sclerosis. Molecular Neurodegeneration 2009 4:1, 4(1), 1-13. https://doi.org/10.1186/1750-1326-4-31

Tutanc, M., Aras, M., Dokuyucu, R., Altas, M., Zeren, C., Arica, V., Ozturk, O. H., Motor, S., \& Yilmaz, C. (2015). Oxidative Status in Epileptic Children Using Carbamazepine. Iranian Journal of Pediatrics, 25(6), 3885. https://doi.org/10.5812/IJP.3885 
TW, L., S, Z., \& YT, W. (2014). Excitotoxicity and stroke: identifying novel targets for neuroprotection. Progress in Neurobiology, 115(C), 157-188. https://doi.org/10.1016/J.PNEUROBIO.2013.11.006

Woronowicz, A., Cawley, N. X., \& Loh, Y. P. (2013). Carbamazepine Prevents Hippocampal Neurodegeneration in Mice Lacking the Neuroprotective Protein, Carboxypetidase E. Clinical Pharmacology \& Biopharmaceutics, Suppl 1, 2. https://doi.org/10.4172/2167-065X.S1-002

Yamamura, S., Hamaguchi, T., Ohoyama, K., Sugiura, Y., Suzuki, D., Kanehara, S., Nakagawa, M., Motomura, E., Matsumoto, T., Tanii, H., Shiroyama, T., \& Okada, M. (2009). Topiramate and zonisamide prevent paradoxical intoxication induced by carbamazepine and phenytoin. Epilepsy Research, 84(2-3), 172-186. https://doi.org/10.1016/J.EPLEPSYRES.2009.01.015

ZH, L., P, L., M, R., \& T, R. (2010). Effect of human pharmaceutical Carbamazepine on the quality parameters and oxidative stress in common carp (Cyprinus carpio L.) spermatozoa. Chemosphere, 80(5), 530-534. https://doi.org/10.1016/J.CHEMOSPHERE.2010.04.046

ZH, L., V, Z., J, V., R, G., J, M., \& T, R. (2010). Modulation of antioxidant defence system in brain of rainbow trout (Oncorhynchus mykiss) after chronic carbamazepine treatment. Comparative Biochemistry and Physiology. Toxicology \& Pharmacology: CBP, 151(1), 137-141. https://doi.org/10.1016/J.CBPC.2009.09.006

Zhu, G., Okada, M., Murakami, T., Kawata, Y., Kamata, A., \& Kaneko, S. (2002). Interaction between carbamazepine, zonisamide and voltage-sensitive $\mathrm{Ca} 2+$ channel on acetylcholine release in rat frontal cortex. Epilepsy Research, 49(1), 49-60. https://doi.org/10.1016/S09201211(02)00015-3 